\title{
A new Xanthodirphia Michener (Lepidoptera, Saturniidae, Hemileucinae) from Costa Rica
}

\author{
Vitor O. Becker ${ }^{1}$ \\ Isidro A. Chacón ${ }^{2}$
}

\begin{abstract}
Xanthodirphia abbreviata sp. $\mathbf{n}$., is described from material collected in high elevations in the mountains of Costa Rica.

KEY WORDS. Saturniidae, Xanthodirphia, Costa Rica, new species, taxonomy
\end{abstract}

Xanthodirphia Michener, 1949, originally proposed as a subgenus of Ormiscodes Blanchard, 1852 includes a single species, X. amarilla (Schaus, 1908), endemic to the mountains of Costa Rica, at high elevations. A second species, sympatric and very similar, is described below based on specimens collected by the authors and from material deposited in the Instituto Nacional de Biodiversidad (INBio), Costa Rica.

\section{Xanthodirphia abbreviata Becker \& Chacón, sp. $\mathbf{n}$.}

Figs 1-4

Males (Fig. 2). Forewings 32-36 mm. Pale yellow. Head dark gray; antennae light salmon. Thorax yellow mixed with fuscous scales dorsally, narrowly bordered vinaceous anteriorly and posteriorly, dark gray ventrally. Wings pale yellow, costa, veins, interspaces and fasciae strongly marked vinaceous to fuscous. Hind wings with well defined PM fasciae. Abdomen dark gray dorsally, sternites bordered with thin row of pale scales basally forming narrow, transverse bands; lateral row of vinaceous scales reaching vinaceous tip of abdomen; two broad, parallel, ill defined, yellow bands bordering a dark gray band ventrally.

Male genitalia (Figs 3-4). Uncus strongly sclerotized towards apex, apex with a strong, triangular indentation; gnathos strongly sclerotized medially, forming a long pointed process; valvae very broad; apex of costa forming a triangular, pointed process; clasper ["inner spine" sensu Michener (1952: 445], well developed, triangular, pointed; vinculum expanded into a broad saccus. Aedoeagus straight, thin, slightly expanded distally.

Female. Unknown [the female of $X$. amarilla is similar to the male, showing almost no dimorphism].

1) Research Associate, Departamento de Zoologia, Universidade de Brasília. P.O. Box 04525 , 70919-970 Brasília, Distrito Federal, Brazil. E-mail: vbecker@rudah.com.br

2) Research Associate, Museu Nacional de Costa Rica and Instituto Nacional de Biodiversidad (INBio). P.O. Box 749-100, San José, Costa Rica. E-mail: ichacon@inbio.ac.cr 
Material studied. Holotype male, Costa RicA, Cartago: Cerro de la Muerte, 3100 m, 17.IX.1999, Becker \& Chacón leg. (INBio, Costa Rica). Paratypes: 2 males same data as holotype (VOB); 12 males, Idem, [Pensión Georgina], $3100 \mathrm{~m}$, 5-7.VIII.1981, Becker leg. (VOB, USNM); 8 males, Idem, 1 km NE Cerro Asunción, 3100 m, 8.IV.1984, Janzen \& Hallwachs leg. (INBio); 2 males, Idem, 24 km S. El Empalme, 2700 m, 3.VII.1986, Gould \& Thomson leg. (INBio); 1 male, Idem, Villa Mills, 3000 m, VI.1985, Janzen \& Hallwachs leg. (INBio); 2 males, Idem, Villa Mills, Quebrada Muerte, 3120 m, 7.VII.1993, Corrales leg. (INBio), 1 male, San José, R. F. Rio Macho, Estación Ojo de Agua, 3000 m, 5-9.IV.1997, Gamboa leg. (INBio).

Remarks. This species is very similar to $X$. amarilla (Fig. 1) and, in case it was allopatric, it could be argued that it represented only a geographic form of the former. However, as it is sympatric and the differences shown by the long series of specimens are constant, with no intermediate forms between the two. The main differences between $X$. amarilla and $X$. abbreviata is size (FW always shorter than $4 \mathrm{~cm}$ in $X$. abbreviata while always longer in $X$. amarilla), and genitalia (apical process of valvae shorter, triangular, in $X$. abbreviata instead of a longer, digital process in $X$. amarilla, and the presence of a well developed, triangular clasper in the former, instead of a reduced, narrow ridge in the latter. Specimens belonging to both forms were compared by the first author with the type of $X$. amarilla in the National Museum of Natural History (USNM), Washington. The large form matches this type.
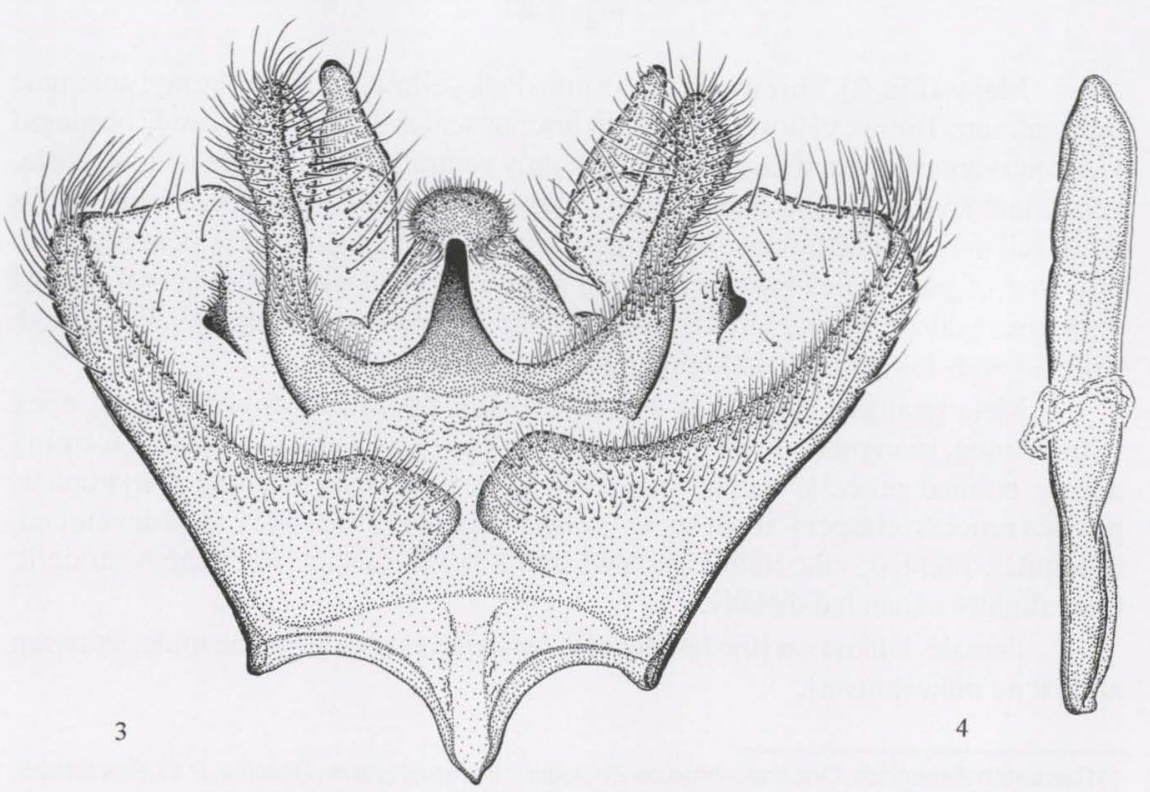

Figs 3-4. Male genitalia of Xanthodirphia abbreviata sp. n., paratype. 

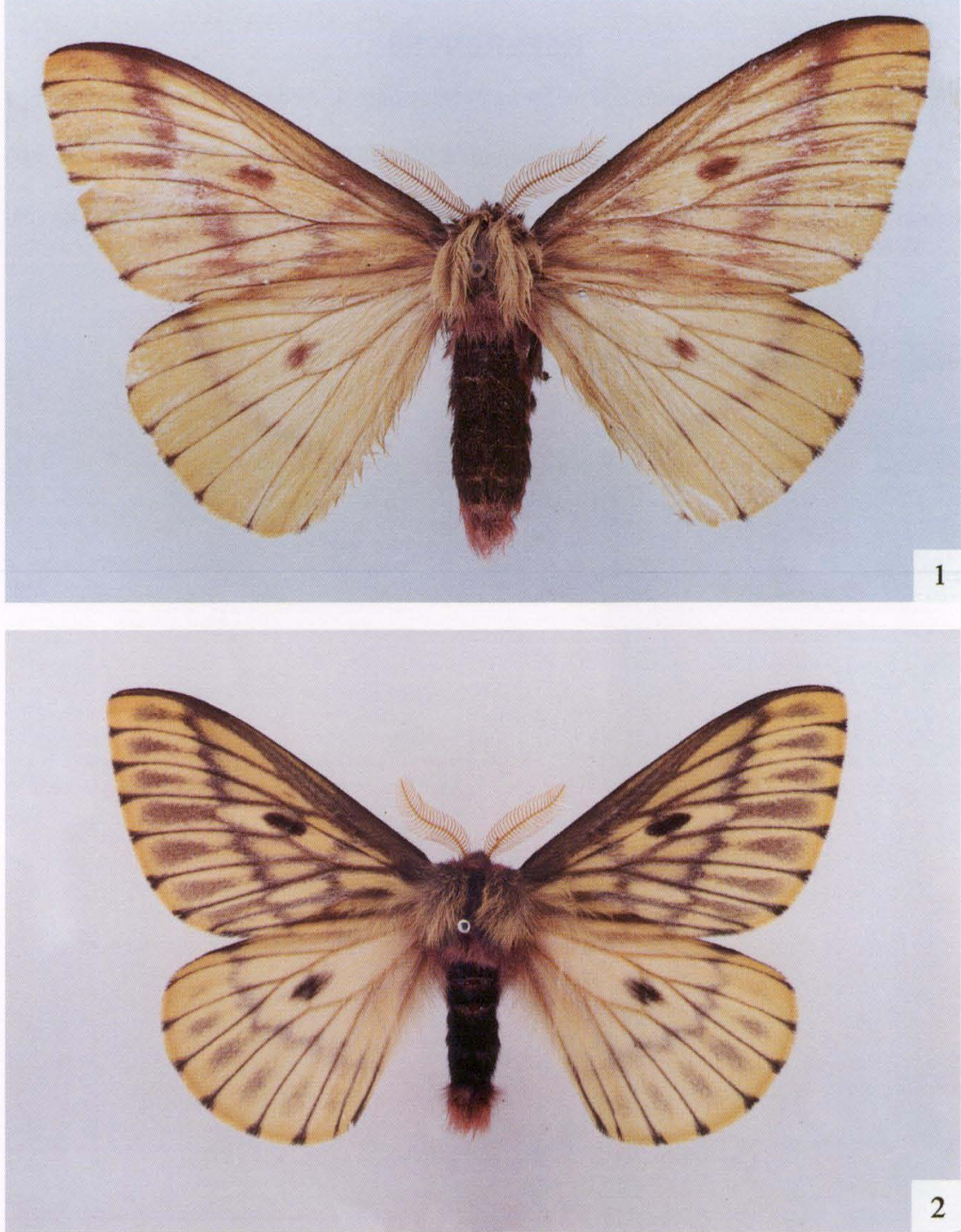

Figs 1-2. Adult males of Xanthodirphia. (1) X. amarilla (Schaus); (2) X. abbreviata sp. $\mathbf{n}$., holotype.

ACKNOWLEDGEMENTS. The authors are especially indebted to Prof. Federico Valverde, Universidad de Costa Rica, owner and manager of the Cerro de la Muerte Biological Station, for his hospitality and permission to collect. The line drawings were done by Wellington Cavalcanti (EMBRAPA-CPAC), Planaltina, DF, Brazil. 


\section{REFERENCES}

MiCHENER, C.D. 1949. New genera and subgenera of Saturniidae (Lepidoptera). Jour. Kans. ent. Soc. 22: $142-147$

1952. The Saturniidae (Lepidoptera) of the Western Hemisphere. Bull. Amer. Mus. nat. Hist. 98: 337-501.

Schaus, W., 1908. Description of three new species of saturnian moths. Proc. U.S. natn. Mus. 34: 65-66.

Recebido em 18.V.2000; aceito em 05.IV.2001. 